\title{
CLINICAL STUDIES \\ IN
}

\section{THE GLASGOW ROYAL INFIRMARY.}

By W. T. GAIRDNER, M.D.,

Professor of the Practice of Medicine in the University of Glasgow.

No. I.

Bronchitis, with Slight Dropsy: Albuminuria: Hypertrophy of Left Ventricle of Heart, and Degenerated Arteries: Arcus Senilis: Relief under Diuretics, elc., well-marked Alteraiion in Cardiac Percussion, and in Position of Apex.-J. B., aged 47, labourer, was admitted to Ward 7, Glasgow Royal Infirmary, October 14th, 1870. This man, after having been under treatment for nearly a month, was submitted to the class for clinical examination on November 12th. A few simple questions brought out the details of a history of bronchitis, with rales, formerly sibilant, now mostly bubbling, in the lungs, the percussion being nearly unchanged throughout. Slight puffiness of the eyelids was then noticed, together with a certain amount of dropsy of the legs, feet, and back. The urine was then examined, and found to be of specific gravity I, Or 2, slightly albuminous (it had been much more so, and had contained granular tube-casts with epithelium). Dr. Gairdner directed attention to the flabby state of the muscular system, and the pallid complexion (the patient had lost two stones in weight). Upon the basis of these elementary facts tending to establish chronic organic disease, an examination was called for into the state of the organs and functions in detail.

The first fact that attracted attention in this more minute examination was the presence of arcus senilis in the corneæ to a considerable extent. Pursuing this line of inquiry, it was found that the anterior temporal arteries on both sides were tortuous and unduly resistant to the touch. A similar condition was discovered in both radial arteries, and, although not so distinctly, in the vessels of the thyroid axis. The superficial femoral on the left side was also distinctly indurated in the greater part of its course. These observations on the arterial system gave special importance to the examination of the heart.

In regard to the percussion of the heart, difficulties had been experienced in the earlier examinations, partly owing to the presumed overlapping of the more or less emphysematous lungs, and partly from the presence of a degree of dulness (perhaps from fluid effusion in the pleura) diffused in the left lateral region. With due care as to details, however, evidence had been obtained of a certain amount of hypertrophy of left ventricle, and the facts recorded with great care on the Ist November supplied an interesting comparison with the results of examination on the 12 th

At the former date, the cardiac apex-beat was felt most strongly in the fifth intercostal space, and more feebly in the sixth, from an inch to an inch and a quarter to the left of the vertical line of the nipple. Both these points had been accurately marked with nitrate of silver. By placing the patient on his left side, the impulse of the apex could be distinctly followed to nearly two inches to the left of the line of nipple. The left margin of the cardiac dulness, so far as could be made out, was in correspondence with the more remote of these two situations, and the upper margin passed through the nipple, affording evidence of a lowered position of the heart, or of slight pulmonary encroachment. The transverse measurement of the dulness at its broadest part was fully six inches.

In almost all these particulars, slight alterations were observed on the I2th November. The apex-beat was chiefly appreciable at a point about half an inch nearer the nipple than the nearest of the points above noticed; and in the sixth intercostal space no impulse could be detected. The percussion-dulness was correspondingly altered. The fact of the marking with nitrate of silver, and the exceedingly distinct character of the apex-beat on the second, though not on the first occasion, made the inference inevitable-either that a diminution in the size of the heart had occurred between the two observations, or that the lung, by being less expanded with air, had permitted the heart to rise up in the thorax, and so brought the apex nearer the nipple.

The sounds of the heart, though not greatly altered, and quite free from murmur, were in harmony with the idea of a certain amount of hypertrophy of the left ventricle. It was noted in the report of November Ist, that "the first sound is a little dull in tone, even at the apex, and the second is somewhat abnormally deepened in tone over the aortic cartilage." These facts continued to be observed on November 12th. Neither the liver nor the spleen showed any distinct abnormality to percussion or otherwise. There was no fever; pulse 70 .

Under the administration of cream of tartar in electuary, and of a stimulating mixture of spirit of chloroform and camphor mixture, this patient had been improving since admission to November Ist, when a partial check occurred, and the bronchitis seemed to relapse, though not nearly so bad as at first. This was gradually relieved, the cream of tartar being given in the form of a drink, the other medicine continued. During the latter part of the month of October, the urine averaged 70 ounces daily. From ist to 6 th November (relapse of bronchitis), the quantity was, on an average, 60 ounces. From the 6th to 12th November, it was 73 ounces on an average; and, at the latter date, 100 ounces in twenty-four hours. There was every reason to think that the improvement in the patient's condition had been commensurate with the increased flow of urine.

REMARKs. - In speaking of this case, Dr. Gairdner said that it was one that in dispensary practice, or under an examination hastily conducted, might very easily have passed as a case of mere chronic bronchitis; and it was therefore a very suitable one, at the commencement of a clinical course, to demonstrate the necessity of careful and thorough examination. The facts indicating disease or degeneration of the heart, arteries, kidney, and cornea, only came out on physical examination, and were by no means brought into notice directly by the statement of symptoms in the first instance. In fact, this patient, who considered himself a fairly healthy man up to the time of his bronchitic attack, is clearly proved to have a constitution organically undermined at a multitude of points, so that the failure of it altogether at no distant date may be regarded as extremely probable. In the meantime, the evident improvement under diuretics, and more particularly the curious physical evidence afforded of improvement in the condition of the heart, are worthy of especial notice. In estimating this latter improvement, however, it should not be forgotten that the over-expansion of the edges of the lungs on admission had a tendency to displace the heart downwards; and it is possible, therefore, that the altered position of the apex may not have been due to any change in the size of the organ; only in such case, the dull percussion ought to have extended rather than diminished; so that, having regard to all the facts, Dr. Gairdner inclines to the belief that the hypertrophied or dilated left ventricle had become somewhat reduced in size, and acquired a greater control over its contents; the improvement in all the symptoms proceeding pari passu.

\section{CAUTIONS IN THE USE OF SURGICAL INSTRU. MENTS AND APPLIANCES.*}

By THOMAS GREEN, F.R.C.S., M.D.Edin., Consulting-Surgeon and late Senior Surgeon to the Bristol Royal Infirmary, etc.

DURING the whole of my professional life I have been intimately connected with large hospitals, either as a student or as Surgeon to the Bristol Royal Infirmary ; and it has thus fallen to my lot to see a good deal of surgery-to witness not alone what its resources can accomplish in the successful treatment of disease or injury, but also serious accidents, often fatal, occurring in the use of surgical instruments or appliances. These cases have been most useful to myself as warnings, and, perhaps, have prevented similar accidents at my own hands. T'o bring them before you in detail may possibly do the same service to others that their observation has done to myself.

In clinical lectures, or in those given at the Medical School, I have always endeavoured to impress on the students the necessity of caution in dealing with the canals passing from within to the different outlets of the body. When instruments are required, there is a delicate mem. branous tube to pass through; and to make this passage we have either a metallic instrument, or one of a different material, but nearly as hard and unyielding. If the instrument do not pass freely and easily, or if there be an obstruction to its passage, anything beyond a moderate amount of pressure or force may make it go through, not the canal, but the membranous structures of which it is composed.

Case of Tracheotomy in which the Trachea was not opened.-A child, suffering from croup, was under the care of Dr. Lyon. In consultation with a surgeon in Bristol, tracheotomy was agreed upon. The operation was at once performed ; the child was not relieved, and died soon afterwards. On examination, it was found that the trachea had not been entered; the cannula lay in front and close on the rings of the trachea. 
The surgeon was a most experienced operator, but his method of performing this operation was to endeavour to enter the trachea. by pushing a lancet through the skin and coverings of the part into the tube. In this case it entirely failed; and the failure may be taken as a caution not to operate in this way.

Having operated more than fifteen times for croup and diseases of the larynx, I have not found any difficulty in entering the trachea by making a slow and careful dissection (if the urgency of the case permit it) through the tissues, next exposing the rings and opening them from the crico-thyroid space downwards as far as may be necessary. The operation was successful as far as it went in all those cases; yet every one of them ended fatally, it having failed, as too often happens, to do more than arrest for a short time the urgency of the symptoms.

Having had such marked want of success when operating for disease, it is but right to say there is a bright side to this picture. I have operated six times for the removal of foreign bodies in the larynx or trachea, and in each case successfully. One case, where I had to operate for what appeared to be disease of the larynx, is worth mentioning, as it imparts a caution in treating similar cases.

Case of Tracheotomy for Supposed Laryngeal Disease, arising from Aneurismal Pressure: Fatal.-A patient in the Bristol Infirmary appeared to be suffering from urgent disease of the larynx. In consultation, tracheotomy was agreed upon, which I immediately performed : the crico-thyroid space was opened, and the rings divided sufficiently to allow a tube to be introduced. No relief followed the operation; and the man died soon afterwards. On examination, no disease of the larynx was found, but aneurism of the arch of the aorta pressing on the left recurrent nerve.

Similar cases have been placed on record where aneurismal pressure on the nerve has caused laryngeal symptoms. It may become a question whether the operation might not be performed simply to give temporary relief to these symptoms; in this case, it failed to give the slightest relief. This patient was under the care of my colleague, $\mathrm{Dr}$ Brittan, in the medical wards, before coming under me for surgical treatment. Dr. Brittan stated at the meeting that in operating I had nearly cut into a pouch from the aneurismal sac, which extended up wards by the side of the trachea. I was not aware of this at the time but, as he examined the parts very carefully after death, I have no doubt that he is correct. The preparation is in the museum of the Bristol Infirmary, and I shall be happy to show it to anyone wishing to see it.

Female Catheter escaping into the Bladder and perforating its Coats : Fatal.-A young woman was admitted into the Bristol Infirmary, under the late Mr. Lowe, said to be suffering from disease of the bladder. The prominent symptoms were acute pain and tenderness over the bladder, extending from the pubes upwards on the left side of the abdomen purulent discharge from the bladder, at times tinged with blood; quick pulse, nausea, vomiting, etc. She stated that she had good health till recently, when retention of urine came on, requiring the occasional use of the catheter. After its last use severe pain came on, constant desire to pass urine, etc. She had been gradually becoming worse until admission. She was driven several miles to the Infirmary, and felt much distress from the shaking of the carriage. What was this disease? $\mathrm{Mr}$. Lowe thought it either an abscess in the left kidney discharging through the ureter, or an ovarian abscess opening into the bladder. He knew nothing of the catheter. Treatment seemed of little use except to relieve pain. She died, worn down by profuse discharge and pain. On examination, the convolutions of the intestines on the side affected were found agglutinated. On separating the adhesions, a female catheter was discovered, lying in a large oblong cavity imbedded in broken-down tissue and pus, with an opening into the bladder.

The case was now clear: the catheter had escaped into the bladder, and, after a time, had perforated its fundus, passed between the convolutions of intestine without wounding the gut, and formed the cavity in which it lay.

The surgeon, if he tried, had not succeeded in extracting it. This was an accident that might happen to any of us; but I think it was blamable to allow the instrument to remain in the bladder. If the surgeon failed to remove it himself, he ought to have sought assistance, or have sent the girl to some hospital, stating what had happened. I may say with some confidence that, if she had come to the Bristol Infirmary we could have taken it out of the bladder; in fact, I have no doubt that any Hospital Surgeon could have done the same.

The caution from this case is obvious. Do not let a catheter slip into the bladder; but, should this happen, take care to remove it.

Female Catheter in the Uterus: Perforation, Extraction, etc.: "Unique Case". - A case somewhat similar has been reported by M. Foltz to the Medical Society at Lyons. A woman introduced a female catheter into the uterus to procure abortion; this was soon effected, but the instru- ment remained in. A minute search was made by the surgeon, but in vain. After four months, a tumour was found at the umbilicus, in which the extremity of the catheter could be felt. An attempt was made to extract it through the vagina by incising the neck of the uterus, but without success. It was afterwards extracted with difficulty through an incision in the abdominal walls. The patient recovered. When the case was related to the Society, some thought the catheter had slipped into the bladder, perforated its coats, passed up between the convolutions of intestine, and formed a cavity between them and the walls of the abdomen, in which it lay. In many things it resembles the case which I have related, but it differed, according to the account given, in that the foreign body did not excite acute inflammation and suppuration along its track. It may, however, have excited enough adhesive inflammation to circumscribe the cavity in which it lay, aud to close it. The case also differed in not terminating fatally. The author considers this case "unique, after having taken great pains to search through many medical periodicals"; so that the report of the one here given may be of interest to the surgical inquirer.

Fatal Wound in the Vagina, caused by a Glass Syringe.-This case occurred lately at Guy's Hospital. It resembles the last case as far as the nature of the injury is concerned, but differs as to the instrument by which the injury was inflicted, and also in the result, this case ending fatally. A young woman used a glass syringe to throw a solution of alum into the vagina. It broke when in the canal. "Great pain and some hæmorrhage" followed on its being removed piecemeal by her friends. She became a patient of Dr. Oldham, at the Hospital, and died twelve days after admission. On examination, there were found two purulent cavities in the abdomen, and a wound in the vagina behind the os uteri. This case gives a special caution against the use of glass syringes in the vagina. I have been informed of other cases where this accident has happened.

The Gut Punctured in Opening a Lumbar Abscess: Fatal.-A man had lumbar abscess and became a patient in a large public institution in Bristol. The surgeon decided to puncture, which he did with a long trocar. The instrument was pushed into the abscess to its full extent; to me it appeared at the time that it was pushed in farther than was necessary. On withdrawing the stilet, no matter came through the cannula, but, on drawing it half out, pus, with some air, came through the instrument. Great pain was felt after the puncture. On the following day, blood came from the anus; afterwards, blood and pus were discharged. Irritation of the gut, tenesmus, etc., followed. The disease was supposed to be dysentery. The man died in a fortnight. On examination, a round fistulous opening was found between the abscess in the back and the descending colon. What had happened now became clear. The trocar had pierced the opposite side of the abscess and gone into the colon. The caution taught here may be thought unnecessary; but the surgeon was considered clever and had much experience, though he appeared to me too rough in the use of penetrating instruments.

Perforation of the Esophagus by a Bongie: Fatal.-A young woman became a patient of mine at the Infirmary. She was sent in for stricture of the œsophagus; her symptoms, however, were those of in flammation of one lung. The treatment was directed to that disease, and nothing was done in reference to the stricture. She could swallow only liquids, but with pain at one part of the tube. An instrument had been passed shortly before admission. Great pain, oppressed breathing, cough, and spitting of blood, followed its introduction. Within a week she died, apparently from acute pneumonia. On examination, it was found that the bougie had been forced through the coats of the osophagus, and had penetrated some distance into the substance of the left lung. The wound had united, but the part where the bougie had gone through was indicated by a ragged surface within the tube, and intense congestion where it had traversed the lung. No stricture existed.

This case proves the necessity of caution in passing an œesophagus bougie, and the same caution is required in passing the tube of a stomachpump. Cases are on record where the latter instrument has been passed through the larynx, and fluid pumped into the trachea.

Perforation of the Rectum by a Bougie: Fatal. - A woman became a patient at the Infirmary for Stricture of the Rectum. She stated that an instrument had been passed into the bowel for stricture two days previously. Great pain, ending in faintness, followed its use. On admission, she was suffering from what appeared to be acute peritonitis, extending over the lower part of the abdomen, on the left side. The treatment was directed to the local inflammation, but the case ended fatally. An examination was made in the presence of my colleague, Dr. Fairbrother, and myself. The bougie had been forced through the coats of the gut, about three inches from the anus. It passed up between the convolutions of the intestine, causing acute inflammation 
and agglutination of all parts in the region affected. There was no stricture in this, as in the last case, so that the diagnoses in both cases were incorrect.

Accidents of this kind have occurred too often. One of them, well known to several gentlemen present, happened in the neighbourhood of Bristol, in the hands of a skilful and experienced surgeon, a man so universally respected that all who knew him sincerely regretted the occurrence. A bougie was passed, and went through the coats of the gut; the lady died soon afterwards; and, what was more melancholy, the accident happened, and she died, in the surgeon's own house.

Injury has not unfrequently been done to the rectum from the tube of the enema-syringe, producing abrasions and laceration of the mucous membrane, contusions, etc. I once treated a case of tetanus by injections of beef-tea, brandy, and laudanum, which at one time appeared likely to be successful. These means certainly prolonged life and relieved the urgent symptoms; the case, however, ended fatally. On examination, the mucous membrane of the gut was found abraded in several places; it appeared to me, by the enema-tube. The elastic tube now much in use is an improvement on the ivory pipe hitherto used; it is less likely to injure the gut, and is longer.

Some years ago, a member of Parliament for a large city in the south of Ireland, caused his own death by an enema-tube forced through the coats of the rectum, in the hurried use of the instrument by himself.

We have a valuable instrument in O'Beirne's long tube ; its value is, I think, not fully appreciated. It will remove obstructions, whether from inflammation, spasm, or obstruction in the bowels, where all other means fail, either medicine by the mouth or the usual injections; if the former consist of strong purgatives, it often makes matters worse. O'Beirne's tube, as now sold by the instrument-makers, is about twenty-eight inches long; it may be introduced to the extent of twelve or fourteen inches into the gut, with cautious manipulation, and not in a hurry. This can be done with perfect safety. If passed so far, it travels well into the left curve of the colon, and two or three pints of warm fluid may thus be thrown through the transverse into the descending colon, even as far as the cæcum. I have treated not a few cases of obstruction in consultation with my colleague, Dr. Lyon, and in every case but one successfully; the plan has succeeded when things appeared hastening to a fatal termination. One case I will mention.

A medical friend at Clifton was under the care of Dr. Lyon and Dr. Symonds. I saw him in consultation with these gentlemen. There were a large hard tumour in the right iliac region; incessant vomiting night and day; constant hiccough ; a feeble and rapid pulse; pale and sweating skin, etc. But one termination could be looked for. Nearly four pints of warm fluid were slowly and cautiously injected by O'Beirne's tube. This succeeded in breaking up and bringing away a mass which appeared to a large extent made up of magnesian accretions. His symptoms soon improved. This gentleman perfectly recovered, and is, I am happy to say, now in perfect health. The tube requires caution, especially when passing the sigmoid flexure. Haste or undue force may here do mischief.

I think enough has now been said to prove the necessity of caution in the introduction of instruments into the rectum.

We now come to consider the most frequent, and most important because most frequent, wounds of membranous tubes caused by instruments; I mean those of the urethra. After many years of hospital experience, truth requires me to say that wounds of the urethra, false passages, etc., made by instruments, are not unfrequent ; and I believe that other hospital surgeons will say the same. The consideration of this subject in reference to the causes and prevention of accidents would extend this paper beyond its intended limits ; therefore I must defer any remarks I may wish to make until a future occasion.

I should have hesitated, perhaps not felt justified, in bringing those cases before you if I could not include myself in the category of those in whose hands accidents have happened. Infallibility belongs not to our profession, although the Council of learned Churchmen now assembled in Rome may decide that it is the attribute of one frail mortal, even though he occupy at best a tottering throne.

A Grooved Needle Broken in a Tumour, and Extracted.-I saw a lady at Clifton in consultation with Mr. Greig. She was suffering from a tumour in the breast, hard, deeply seated, apparently lying under the gland. We decided to use the grooved needle, which I then introduced. The depth of the induration required it to be passed to its entire length. In attempting to withdraw it, the needle broke off, leaving about an inch deeply imbedded in the part. What was to be done? Leave it in, and trust to the chapter of accidents to deal with it? This we decided not to do, but at once to cut it out. On making two or three deep incisions, I was able to draw it out without any difficulty. The wound healed by immediate union. We said nothing about it, and the lady and her friends never knew that any accident had happened.

The grooved needle as a means of diagnosis is a most valuable little instrument, and is not used as often as it ought to be. The caution to be drawn from this case may not be altogether useless.

Supposed Abscess: Puncture: Proved to be Aneurism: Fatal.-The very common operation of opening an abscess requires some caution in its performance. The tactus erntditus of the experienced surgeon sometimes fails to give a correct diagnosis; and accidents have happened, sometimes serious, even fatal, when an error in diagnosis has been made.

Among the serious accidents may be mentioned opening an aneurism supposed to be a collection of pus. I have myself known this to occur; but there is one well known case of which it may be well to remind you. It occurred in the hands of one of the most accomplished surgeons of his day. Mr. Liston has published the case himself; it may therefore be referred to, and his name be mentioned. Briefly stated, the case was as follows. A boy became a patient in University College Hospital with swelling at the side of his neck. It was shown to Mr. Liston on his going round. He examined it, pronounced it to be an abscess, and passed a bistoury into it. Arterial blood came out in a full stream, and left no doubt as to what the swelling was-aneurism of the carotid artery. Subsequently, Mr. Liston tied the vessel. The boy died; and dissection proved the tumour to be an aneurism. It is but justice to the dresser of the case to add, that he had carefully examined the swelling, considered it to be aneurism, and told Mr. Liston his opinion. That gentlemen thought otherwise, the result being as just stated.

Eminent men make mistakes from over-confidence in their powers of diagnosis, which less eminent men avoid by a more careful examination.

Abscess in the Tonsil Punctured: Fatal Hamorrhage.-A fatal accident occurred some years ago at the hands of one of the most distinguished surgeons in Ireland. In opening an abscess in the tonsil, the instrument wounded one of the large vessels passing near the gland. A gush of blood followed, and the young lady died at once; and, more sad to tell, it was said that she died in the arms of a medical student to whom she was engaged.

Wound of an Artery in Opening an Abscess, supposed to be Malignant Disease. - The following case occurred to myself, and is not without interest. A lad was brought into the Bristol Infirmary. On admission, one side of his face was much swollen and covered with layers of lint, strapping, and bandage, apparently to stop bleeding. They were all saturated with blood, and a weeping of blood was going on under these coverings. The history was, that the swelling was thought to be an abscess, and was punctured by a surgeon; no pus, but blood followed the puncture. The case was then thought to be one of malignant disease, and was sent to the Infirmary as a case of fungoid disease of the face. The lad became my patient. Bleeding was still going on, and he looked pale; it therefore became necessary to know at once what the disease really was. The coverings were all taken off, and the part well sponged. The swelling felt "doughy"; it wanted the hardness of scirrhus and the soft elastic feeling of fungus. In the centre of the cheek was an ulcerated opening, through which dark blood was oozing at the time. On passing a finger through the opening, it appeared to enter a large cavity filled with coagula. On withdrawing the finger, it was covered with blood and small coagula. I determined at once to lay open this cavity freely, to clear away its contents, and know what it really was. This I did immediately; and, the exposed parts having been well cleaned, an artery was found bleeding, which I tied. It seemed to be either the facial or one of its primary branches.

The conclusion to be arrived at is, that the instrument used in opening the supposed abscess wounded the artery. Blood issuing from the puncture, the wound was immediately closed, and constant pressure kept up to stop the bleeding, the coagula being kept in by this pressure. The swelling, no doubt, was from that form of inflammation in which there is more fluid than solid exudation, giving a deceptive feeling of suppuration. We have often seen these swellings opened when there was no pus formed. I think this case gives us a caution not to be too hasty in making a diagnosis of malignant disease ; and it also confirms a most useful rule of practice, which is, where pressure fails to arrest bleeding from a deep surface or cavity, at once to lay the parts open freely, and thus ascertain whence the bleeding comes, whether from one vessel which can be tied, or from a number of minute ones, where styptics can be applied. Cases occur where bleeding goes on a few days from a stump, say after amputation of the thigh. A large gush of blood comes on suddenly, and is supposed to come from the main artery, so as to lead the surgeon to think of tying the vessel above the wound. Let the wound be freely laid open, if necessary, adhesions separated, 
and the entire surface exposed to view. There may be some oozing of blood going on, or, more often, the mere exposure to air at once arrests any further hæmorrhage ; and in some cases the exposed surface of the stump looks like sodden skin, showing a want of vital power and consequent failure to throw out granulations-the only process by which the wound can be filled up, aided of course to some extent by vital contraction in the surrounding parts. Any stimulating dressing in such a case as this now brings on a healthy condition on the face of the wound. A case precisely similar to the one described occurred in the Infirmary, where more than a pint of blood was lost in a gush. The tourniquet was at once applied, and I was sent for. By the advice of a very experienced colleague (the late Mr. Lowe), the artery was not tied, but the stump was opened in the way described. Not a drop of blood could be seen, merely the sodden surface just described. The large bleeding must have been from the surface ; it was kept in by the dressings, had accumulated until the wound was mechanically distended by the large amount of fluid and could contain no more, when it suddenly burst through the coverings; and this led to the supposition that the main artery had given way.

In both these cases the wound healed rapidly under the usual applications, and without the use of carbolic acid or an invasion from those "septic germs" supposed by some to be such potent agents for mischief.

The healing of wounds is a subject which has lately been so prominently brought before the profession, that I cannot conclude these remarks without taking the opportunity of giving one more caution, which is, not hastily to accept the doctrines now taught by Professor Lister. Most of those present will, I think, agree with me, that there is nothing new in much of this system. There is nothing new in the attempt to convert a compound fracture into a simple one, by closing the external wound and excluding the air; and the same may be said of other wounds. There is nothing new in the "antiseptic" treatment ; every one knows that antiseptics have been freely used by hospital surgeons for many years. There is nothing new in the doctrine that wounds can heal without granulation and suppuration : this doctrine was taught by Macartney in his lectures at the University of Dublin, and published in his work on Inflammation. Having been a pupil, and afterwards assistant, to that distinguished teacher, I was a convert to his opinions : and when I became surgeon to a large hospital, I fully carried out his views, and only gave them up on becoming convinced that they were untenable in practice.

What is really new is the carbolic acid treatment of wounds. This application will, I am confident, be found no better than other remedies of the same class which we already possess ; it is either an escharotic, stimulant, or astringent, according to the proportions used; and I cannot but think that to "putty" over or by any other contrivance to keep in pus, which is, as it were, struggling to get out, is more likely to retard than to hasten the healing of a wound, and is opposed to one of the most important rules of surgery - always to promote the discharge of pus. This fluid, if allowed to remain, decomposes, in hot weather quickly, and then becomes the most frequent cause of pyæmia

If the new system be true, then the principles of John Hunter are false ; and the doctrines contained in Hunter's immortal work on Inflammation, accepted and taught by the best teachers in these countries during the present century, are entirely fallacious. Not alone the present able teachers in London, but the great men who have just passed away, men whose names shed a lustre on our own time, and whose recorded opinions influence the practice of surgery throughout the civilised world-Abernethy, Cooper, Lawrence, Brodie, Travers, and Bellhave taught and written what is erroneous. But it is not so; Hunter's principles will stand as the rule of practice in surgery long, very long, after the new system will have been pronounced by the profession as unsound in theory and erroneous in practice.

"Organic germs", with their most extraordinary performances, make up no small part of the new system. It may be true that there is an amount of animal and vegetable life in a minute form to be found in certain conditions of the atmosphere. But we know so little about those germs, their generation, conditions under which they live, or their influence in the generation or propagation of disease, that we can in the present state of our knowledge admit nothing more about them than that they are ready at hand to perform a part in any hypothesis which a fertile imagination may allot to them. Pasteur's opinions about these germs are being disproved in France, and the same fate seems in store for the startling announcement made by Professor Tyndall. The practical suggestion, to open an abscess with a hot knife to burn out these terrible germs, approaches so closely to the ludicrous, that I suspect the profession will not adopt it.

In conclusion, I take leave to say that nothing is further from $\mathrm{my}$ intention than to impute blame to any one. Accidents have happened and will happen to the best men. During a lengthened education, I have seen them happen to those who deservedly stood high in their profession: but if the relation of these cases can save one life from similar accidents, and perhaps one sensitive mind from the reflection of having occupied the foreground in one of these sad pictures, then this chapter of accidents has not been read in vain.

\section{RECOLLECTIONS OF WORK IN AN AMBULANCE.}

\section{By WILlIAM MAC CORMAC, F.R.C.S., Surgeon to the} General Hospital, Belfast.

\section{VI.}

September 12th.-All our tents were pitched : these were thirty-six in number. They were soldiers', not hospital tents, and calculated to hold eight persons each. We considered four about the proper number. They were spread over the hospital enclosure, now made clean, and trenches had been dug round them. We were distributing some of our cases amongst them, when the even tenour of our way was disturbed by the arrival of a message to prepare to receive a number of fresh cases, and forthwith the patients appeared, borne upon stretchers. The weather was as bad as bad could be, cold and stormy, and the rain came down in torrents, without a moment's cessation. The inequalities of the coverlets over the men served but to form receptacles for little pools of water. There were one hundred and thirty of these poor fellows, all French, sent up to us that fearful day. Some of them were in a truly wretched plight. These patients were transferred to us from the ambulance installed in the fine large building of the College or District Public School, previously occupied by the wounded French, who were removed by the German authorities to make room for their own wounded; and this was done, under the circumstances which $I$ have detailed, in most villainous weather. These patients were not convalescents. There were amongst them two cases of tetanus. Onej of the patients died on the day of his arrival; two died the following day; several in three or four days afterwards. Some absolute necessity for it, or some adequate explanation, may be forthcoming of what certainly appeared to us at the time, and under the circumstances, a most unkind and cruel act. I, for one, should be delighted to receive some explanation. But, as it stands, the case seems to me to be a distinct violation of the Geneva Convention, since a wounded man becomes ipso facto a neutral, and should cease, so far as the doctors are concerned, to possess any nationality whatever. I would not dwell upon this topic, but that it had so direct and unfortunate an influence upon our own well-being. Upon the accession of so many fresh cases, the hospital became at once fearfully overcrowded. One hundred and five of the new-comers had sustained serious injuries, demanding in many instances severe operations; the remaining twenty-five were cases of fever and dysentery.

Very few days passed until the wounds of those previously under treatment began to alter in appearance for the worse. Secondary hæmorrhage became frequent; and, worst of all, some of our best and most promising cases of operation began to show symptoms of pyæmia. All the patients, in fact, sickened more or less. The difference was felt even amongst the staff; for one and all of us got attacks of some sort of illness. One had severe diarrhœe, another a feverish attack, a third violent headache, a fourth an attack of vomiting, and so on. Dr. Sims alone was exempt.

There can be little doubt that the overcrowding which we suffered from at this time was a most potent cause in inducing an increased death-rate. For instance, in thirty-three cases death arose from acute pyæmia, in its most typical form of rigors, drenching sweats, diarrhœea, jaundice, and finally death; the post mortem examinations revealing abscesses, often in the joints and limbs, but more frequently in the liver and lungs, never in the spleen or kidneys. Without doubt, the agglomeration of bad cases has, whatever else may have, a good deal to say to the production of pyæmia. That many other deaths were due to the same cause I am very certain, although it has not been so noted.

Amongst those admitted during the first two days of September, and those sent in on the 9 th, loth, and 12th, the deaths from this cause were about equal, namely, seventeen of the one class, and sixteen of the other. It is perhaps noteworthy that of the seventeen deaths from pyæmia, occurring amongst our original patients, twelve took place between the 21st and 27 th days of the month, seven of the twelve being on the 2 Ist and 22nd September. Again, eight of the sixteen deaths from pyæmia amongst the patients admitted from the 9 th Sept. to the 12th September took place also from the 20 th to the 27 th of the month, five of the eight being on the 20th, 2Ist, and 22nd September. Assuming the duration of a case of acute pyæmia to be from ten to fourteen days, this would determine the commencement of the disease 